Autora: Ideusa Celestino Lopes

Titulação: Professora Doutora. Cursando pós-doutorado na Universidade Federal do Ceará com a supervisão do prof ${ }^{\circ}$ Dr. Evanildo Costeski

Afiliação Institucional: Universidade Estadual Vale do Acaraú - UVA /CE/Sobral

E-mail: ideusalopes@gmail.com

\title{
RESENHA
}

\section{FÍSICA DE ARISTÓTELES}

ARISTOTELE. Fisica. Texto grego a fronte. Curatore R. Radice. Milano: Bompiani, editore, 2011. Pág. 1.134. (Collana: Il pensiero occidentale)

A obra Fisica de Aristóteles, ainda não está totalmente traduzida para o português, apenas os Livros I e II. O texto é composto por oito Livros no total. A coletânea de textos que conhecemos como Física, faz parte das obras denominadas acromáticas, ou seja, uma série de apontamentos que poderiam ser desenvolvidos numa possível apresentação oral. Não existe uma continuidade linear entre os Livros, apesar de ter um fio condutor, que é a discussão sobre a Physis. Mas essa é uma característica que se encontra também, por exemplo, na Metafísica, que deve ser lida com esta mesma reserva. Um exemplo que coloca tal estrutura em evidência são os Livros I e VII, que podem ser considerados completos e autônomos. As partes que compõe o texto foram recolhidas e sistematizadas por dirigentes da escola peripatética, considera-se que Andrônico di Rodi (I a.C.) teria feito a seleção e organização do material.

O objeto de discussão da Fisica é a natureza e as coisas que são da natureza. O que Aristóteles caracteriza como sendo natureza? O que tem em 
si mesmo o princípio do movimento. O termo movimento compreende geração e corrupção; alteração; crescimento e diminuição; translação. A questão central, portanto, do texto é uma investigação sobre os princípios e as condições estruturais do devir, colocados como tema de consideração filosófica. Neste sentido, há uma preocupação com os fundamentos do devir. Trata esse tema nos três primeiros Livros, mostrando o que é o movimento e em que modo ele é inegável e evidente.

Aristóteles está dialogando com os pré-socráticos, que consideravam a Physis como expressão do real na sua totalidade. No entanto, nas suas investigações, faz uma indagação sobre a totalidade e sobre a natureza, distinguindo-as. Mas apesar dessa separação, considera importante a investigação dos princípios para fundação de uma física, como ciência.

Outro interlocutor é Platão, que considera como sendo impossível uma ciência do devir, pois o objeto da ciência deveria ser o imutável e o permanente, o ser. Para Aristóteles, não obstante, o ser é devir, neste texto expõe as razões para se compreender o devir como inteligibilidade. Ao propor a física como ciência se contrapõe diretamente a Platão e Parmênides.

A obra está dividida em oito Livros. No Livro I, defende a construção de uma nova ciência, a Física. Ao apresenta-la como ciência, delineia que a sua tarefa deve ser a de investigar as causas e os primeiros princípios, ou seja, indagar sobre a estrutura que torna inteligível o devir. Mas ao fazer uma abordagem sobre a física como ciência se contrapõe diretamente a Platão e aos Eleatas (Parmênides e Melisso), que negam o estudo da física como ciência do ser no devir. Aborda a tese eleática da unidade e imobilidade do Ser. Analisa em seguida as teses dos que colocam o infinito como princípio, ou infinitos elementos como princípio. Defende que se deve assumir um

\begin{tabular}{|l|l|l|l|l|}
\hline Q Povista Dialectus & Ano 8 & n. 14 & Janeiro - Julho 2019 & p. 320 - 328 \\
\hline
\end{tabular}


número finito de princípios como fundamento do devir. Aborda também algumas teses dos physis que defendiam os contrários como sendo princípios. Aristóteles faz a defesa de que o devir é princípio, assim sendo, seria preciso identificar se esses são um ou mais de um; finitos ou infinitos e se pertencem a um único ou a múltiplos gêneros. Refuta a possibilidade de que os princípios possam ser um ou em número infinito.

\section{Livro II}

A análise sobre os princípios do devir e do devir como princípio, iniciada no Livro I tem continuidade neste segundo Livro. Faz uma abordagem sobre o significado de natureza (physis), como sendo princípio e causa do movimento (kìnesis); apresenta a diferença entre os entes que são da natureza dos que pertencem à arte (técnica). Os primeiros têm em si mesmo o princípio do movimento. A partir dessa argumentação distingue os âmbitos da física e da matemática. $\mathrm{O}$ físico estuda a forma, mas em referência à matéria. Neste Livro, introduz a doutrina das quatro causas como princípio de explicação dos eventos naturais, dando destaque à causa final.

\section{Livro III}

Indaga sobre a estrutura do movimento. Divide o texto em dois momentos: num primeiro momento, dedica-se ao movimento de modo geral, indagando sobre os predicados comuns do movimento (infinito, lugar, vazio, tempo, contínuo), ou seja, sobre as condições estruturais sem as quais o movimento mesmo não pode ser concebido. Num segundo momento, trata especificamente do infinito (àpeiron) como sendo o predicado que é inerente a todas as determinações estruturais no movimento, enquanto contínuo (synechès). Inicia a abordagem sobre o conceito de contínuo, que não se conclui neste Livro, mas apenas no Livro VI.

\section{Livro IV}

Dar continuidade à discussão sobre o que ele chamou anteriormente de "predicados comuns" do movimento. O primeiro a ser tratado é o lugar, aborda o problema da sua existência e em seguida indaga sobre a sua essência. Sua intenção é esclarecer a diferença entre lugar e os seguintes

\begin{tabular}{|l|l|l|l|l|}
\hline Q Povista Dialectus & Ano 8 & n. 14 & Janeiro - Julho 2019 & p. 320 - 328 \\
\hline
\end{tabular}


termos: forma, matéria, intervalo e limite extremo. Segundo Aristóteles, essas são estruturas sem as quais o movimento não é possível. Apresenta a seguinte definição de lugar: como sendo "o primeiro limite imóvel daquele que contém". Trata também da relação que ocorre entre lugar e o todo. $\mathrm{O}$ mundo entendido como todo não tem um lugar, mas cada coisa determinada, por natureza, tem o seu lugar determinado.

O próximo tema a ser tratado é o tempo. Ao analisar os argumentos a favor e contra a existência do tempo, concebido como composto de passado e futuro, faz uma analise sobre a questão do instante, que deveria ser compreendido como indiscutivelmente presente, e como limite. Conclui, não obstante, que tanto a sua existência como a sua essência permanece uma aporia, e que é difícil sustentar que o tempo é movimento, mas também que não é sem movimento. Mas se o tempo for considerado como número pode ser definido como "número do movimento no intervalo entre antes e depois". Nesse sentido, as coisas são no tempo, quando medidas pelo tempo na sua existência, ou seja, as coisas sofrem ação do tempo, e são no tempo, somente enquanto possam ser ou não ser.

\section{Livro V}

Nesse livro tratará o movimento enquanto mudança (metabolé). Inicia introduzindo uma diferença entre mudança e movimento, mudança por si e por acidente; determina as espécies de mudança que procedem de um substrato a um substrato ou de um substrato para um não-substrato, ou seja, entre geração e corrupção. Compreende que movimento se dá de um substrato para um outro substrato, descartando que exista um movimento do não-ser. Discute também a diferença entre movimento e repouso (privação do movimento). Identifica como sendo três as categorias do movimento: qualidade (alteração), quantidade (crescimento e diminuição) e lugar (deslocamento). Trata também do tema da unidade do movimento, como contínuo, e da sua unicidade, como sendo uniforme.

Livro VI

Retoma a discussão sobre o contínuo, que está intrinsicamente ligada aos "paradoxos" de Zenão, que defende o devir como contraditório. Procura demonstrar que o corpo em movimento não se move através de uma

\begin{tabular}{|l|l|l|l|l|}
\hline Q Povista Dialectus & Ano 8 & n. 14 & Janeiro - Julho 2019 & p. 320 - 328 \\
\hline
\end{tabular}


quantidade infinita de processos ou etapas. Tendo como pressuposto que as grandezas não são compostas por pontos ou o tempo por instantes indivisíveis. Refuta, portanto, o argumento da flecha, que percorre certa distância, aparentemente, mas no final das contas está em repouso. Pois entende que o contínuo é um aspecto importante na constituição do movimento que envolve o sujeito, o espaço e o tempo.

Em seguida faz uma análise e uma demonstração da continuidade da grandeza, que tem como consequência que as partes são sempre divisíveis. O tempo também é constituído pelo contínuo. A infinitude deve ser atribuída a um dos dois, ou seja, à grandeza ou ao tempo. Defende a seguinte posição: nenhum contínuo é composto pelo indivisível, mas por partes sempre divisíveis.

Afirma que a grandeza não é composta por pontos, nem o tempo por instantes, ou o movimento por unidade simples de movimento. Trata do instante no tempo, mostrando em que sentido ele é indivisível e idêntico. No instante não é possível nem o movimento nem o repouso, que acontecem somente no tempo. Passa ao exame da mudança, mostrando que não existe um "primeiro" termo no qual o objeto que muda completa a sua mudança. Segundo Aristóteles, existe uma circularidade entre mudança ocorrida e mudança que está ocorrendo. Faz uma análise do tempo a partir do movimento e do repouso, demonstrando que não existe um tempo primeiro do movimento, nem do repouso, mas em cada parte do movimento e do repouso, deve-se compreender o corpo como um inteiro.

A partir da recíproca implicação que existe entre tempo e movimento, tira como conclusão que em um tempo infinito não pode se desenvolver um movimento finito, nem um movimento infinito em um tempo finito. $\mathrm{O}$ infinito não pode ser pensado como ato, mas como potência.

\section{Livro VII}

Neste Livro Aristóteles aborda o movimento na relação entre o motor (o que move) e o que é movido. O ponto de partida é a proposição: "tudo aquilo que está em movimento, necessariamente é movido por si ou por outro". Introduz a existência de um primeiro motor e de um primeiro movimento. Determina que entre o que move e o que é movido não há

\begin{tabular}{|l|l|l|l|l|}
\hline Qevista Qialectus & Ano 8 & n. 14 & Janeiro - Julho 2019 & p. 320 - 328 \\
\hline
\end{tabular}


intermediário. O primeiro motor não está separado do que é movido, mas o motor é princípio do movimento.

Individualiza três tipos de movimento: local, quantitativo e qualitativo. Para tanto aborda os conceitos de impulso, força, repulsão, lançamento. Em seguida analisa o movimento de alteração, mas distinguido entre geração e corrupção, ou seja, geração e corrupção não são formas de alteração em geral, mas apenas de modo acidental. A alteração ocorre somente na parte sensível da alma. Por exemplo, o ato cognoscível não tem geração.

Na sequencia afronta o problema da comparação entre os movimentos: se se pode comparar um movimento com outro. Para Aristóteles não é possível comparar as coisas que são homônimas. A comparação somente é possível se a mudança ocorre na mesma velocidade. Os movimentos diferem ou por gênero, espécie ou número. Discute a questão da comparabilidade entre as varias formas de alteração e entre geração e corrupção.

Afirma também o caráter unitário do movimento, que deve ser considerado sempre no seu aspecto global e unitário. Individualiza os momentos que constitui o movimento: força do motor, grandeza do que é movido, distância e tempo. Demonstra que eles são inerentes ao ato do movimento. Nessa abordagem está confrontando o argumento de Zenão do "grão de milho".

\section{LIVRO VIII}

No último Livro, procura demonstrar a existência de um princípio primeiro do movimento, ou seja, o primeiro motor ou motor imóvel, que move sem ser movido. A argumentação parte da tese de que o movimento é eterno, ou seja, não tem início nem fim.

Nessa relação que envolve motor e movimento, Aristóteles aponta para um primeiro princípio absoluto do movimento, que deve ser eterno e imóvel. O que é movido por este princípio eterno, deve ser eternamente em movimento, enquanto efeito de uma causa eterna. Entre os movimentos existentes somente o movimento circular tem os requisitos da eternidade, uniformidade e identidade. Portanto, o movimento circular eterno pede um princípio por sua vez eterno, que seja imóvel e incorpóreo. O primeiro motor

\begin{tabular}{|l|l|l|l|l|}
\hline Q Povista Dialectus & Ano 8 & n. 14 & Janeiro - Julho 2019 & p. 320 - 328 \\
\hline
\end{tabular}


imóvel é identificado como estando na esfera mais externa do universo. Assim, a Fisica coloca como princípio primeiro de todo o movimento, um princípio metafisico. Um princípio primeiro que é eterno, imóvel, incorpóreo, ou seja, uma realidade que transcende a totalidade do devir, mesmo se a ele é estreitamente ligado.

O problema a ser resolvido: relacionar o Primeiro Motor com a afirmação da eternidade do devir e do mundo. Nesse aspecto está refutando Platão, que no Timeu afirma a origem do mundo e do devir a partir do Demiurgo. A questão da eternidade do movimento é desenvolvida inicialmente a partir da análise histórica dos pré-socráticos, os physicos, que de um modo geral afirmam a existência do devir. No entanto, não há unidade quanto à questão da eternidade. Aristóteles pretende demonstrar a eternidade do movimento, fundamentada em três pilares: definição, motor e eternidade do tempo.

A natureza é princípio de ordem, neste sentido, não estaria sujeita a variação, do ser e do não ser. Toda a argumentação sobre a não geração e não destruição, portanto, da eternidade do devir depende da posição da eternidade do tempo. Ou seja, da impossibilidade de um início absoluto do tempo ou um fim absoluto. O tempo não tem um começo e nem um fim.

Aristóteles faz uma forte crítica aos argumentos contra a eternidade do movimento, que envolve tanto as coisas animadas e os quatro elementos naturais, que se movem sempre do mesmo modo verso o lugar natural, eles têm em si uma disposição inata para receber o movimento. Mas ao mesmo tempo considera que o movimento dos elementos naturais é realizado por natureza, mas não por si. Faz distinção entre o que é movido por si, por outro, por natureza e contra a natureza. Ressalta também que existe uma diferença com respeito aos movimentos dos seres vivos. Introduz os graus da potência e do ato. Se não for impedido, o que é em potência passa a ato.

Faz uma discussão sobre se o motor move por si mesmo, ou por causa de outro, ou ainda, por motores intermediários. Para não ir ad infinito, de um motor que move outro, coloca a existência de um primeiro motor, que move sem ser movido. Demonstra que o primeiro motor move a si mesmo, esclarecendo ao mesmo tempo em que modo se move o motor que move a si mesmo. As partes do motor não estão reciprocamente em movimento, o

\begin{tabular}{|l|l|l|l|l|}
\hline Q Povista Dialectus & Ano 8 & n. 14 & Janeiro - Julho 2019 & p. 320 - 328 \\
\hline
\end{tabular}


motor não é composto de partes que movem a si mesmo, "não é possível que aquilo que move a si mesmo seja movido em modo tal que alguma das suas partes seja movida por outra". Em conclusão, o motor em sentido primário é imóvel. Defende a unicidade do motor imóvel e sua eternidade. Os astros, por sua vez, são motores movidos de tipo particular. Discute, portanto, em que modo o movimento é transmitido ao mundo.

Ao considerar que o movimento deve existir sempre sem interrupção, deve existir algo eterno que move como primeiro motor imóvel. Faz uma argumentação da eternidade do primeiro motor, mostrando de modo contrário a Platão, que o seu conceito de eternidade não é fundado sobre o conceito de alma, que move a si mesma.

Trata de indicar qual movimento o primeiro motor realiza. Em primeiro lugar, deve ser um movimento que é primeiro e contínuo. O movimento local é o primeiro entre os movimentos, e por ser primeiro, ele está implicado nos outros movimentos, ou seja, naquele do crescimento e da diminuição e naquele qualitativo. Conclui que nenhum outro movimento pode ser contínuo, com exceção do movimento local. São vários os movimentos locais, entre eles apenas um é primeiro e contínuo. O movimento retilíneo não é contínuo, por isso, esse tipo de movimento não tem nem mesmo unidade. Somente o movimento circular é contínuo e infinito. Nesse sentido, o movimento circular é o primeiro dos movimentos locais, portanto, tem prioridade em relação ao movimento retilíneo, pois este se destrói, enquanto o circular é eterno. O movimento circular tem continuidade e unidade.

Finalmente faz uma análise e demonstra quais características compete ao primeiro motor: não tem grandeza, ou seja, algo finito, de fato, não pode mover-se em um tempo infinito, nem ter uma força infinita. Percebe-se descontinuidade nos movimentos produzidos por um motor que é por sua vez movido. O primeiro motor é privado de grandeza e assim indivisível, e move o movimento eterno em um tempo infinito.

A Fisica faz uma análise geral sobre o movimento e o repouso na natureza, procura refutar tanto a tese dos que afirmam "tudo está em movimento" tese de Heráclito; bem como os que defendem "que tudo está em repouso", os Eleatas. Aristóteles procura afirmar que algumas coisas são

\begin{tabular}{|l|l|l|l|l|}
\hline Q Povista Dialectus & Ano 8 & n. 14 & Janeiro - Julho 2019 & p. 320 - 328 \\
\hline
\end{tabular}


sempre em repouso, outras sempre em movimento, outras às vezes em repouso e em outros momentos em movimento. O motor imóvel, no entanto, está sempre em repouso. Os elementos naturais se movem, mas também tendem para o repouso.

\begin{tabular}{|l|l|l|l|l|}
\hline Govista Dialectus & Ano 8 & n. 14 & Janeiro - Julho 2019 & p. $320-328$ \\
\hline
\end{tabular}

